Supplement of Biogeosciences Discuss., 11, 13433-13453, 2014

http://www.biogeosciences-discuss.net/11/13433/2014/

doi:10.5194/bgd-11-13433-2014-supplement

(C) Author(s) 2014. CC Attribution 3.0 License.

(c) (i)

Supplement of

\title{
A $22570 \mathrm{yr}$ record of vegetational and climatic change from Wenhai Lake in the Hengduan Mountains biodiversity hotspot, Yunnan, Southwest China
}

Y. F. Yao et al.

Correspondence to: Y. F. Yao (yaoyf@ibcas.ac.cn) and C. S. Li (lics@ibcas.ac.cn) 


\section{Supplementary material}

Figure S1. A comparison of palynomorphs recovered from the Wenhai core and surface samples

Figure S2. A selection of palynomorphs recovered from Wenhai core sediments. 1,17. Polygonaceae, 2. Caprifoliaceae, 3. Ericaceae, 4. Tilia L., 5,6. Quercus L., 7. Compositae, 8,9. Betula L., 10. Loranthaceae, 11,12. Oleaceae, 13. Hamamelidaceae, 14. Castanopsis (D.Don) Spach ., 15. Rosaceae, 16. Ulmus L., 18. Alnus Mill., 19. Artemisia L., 20. Cyperaceae, 21. Caryophyllaceae, 22. Gramineae, 23,24. Umbelliferae, Scale bar $=50 \mu \mathrm{m}$

Figure S3. A selection of palynomorphs recovered from Wenhai core sediments (continued). 1. Abies Mill., 2. Picea Dietr., 3,4. Tsuga Carr., 5,6. Pinus L., 7,16. Polypodiaceae, 8,9. Pteris, 10,11,13,14. Gymnogrammaceae, 12. Dennstaedtiaceae, 15. Athyriaceae, 17. Cyatheaceae, Scale bar $=50 \mu \mathrm{m}$ 


\section{Surface samples}

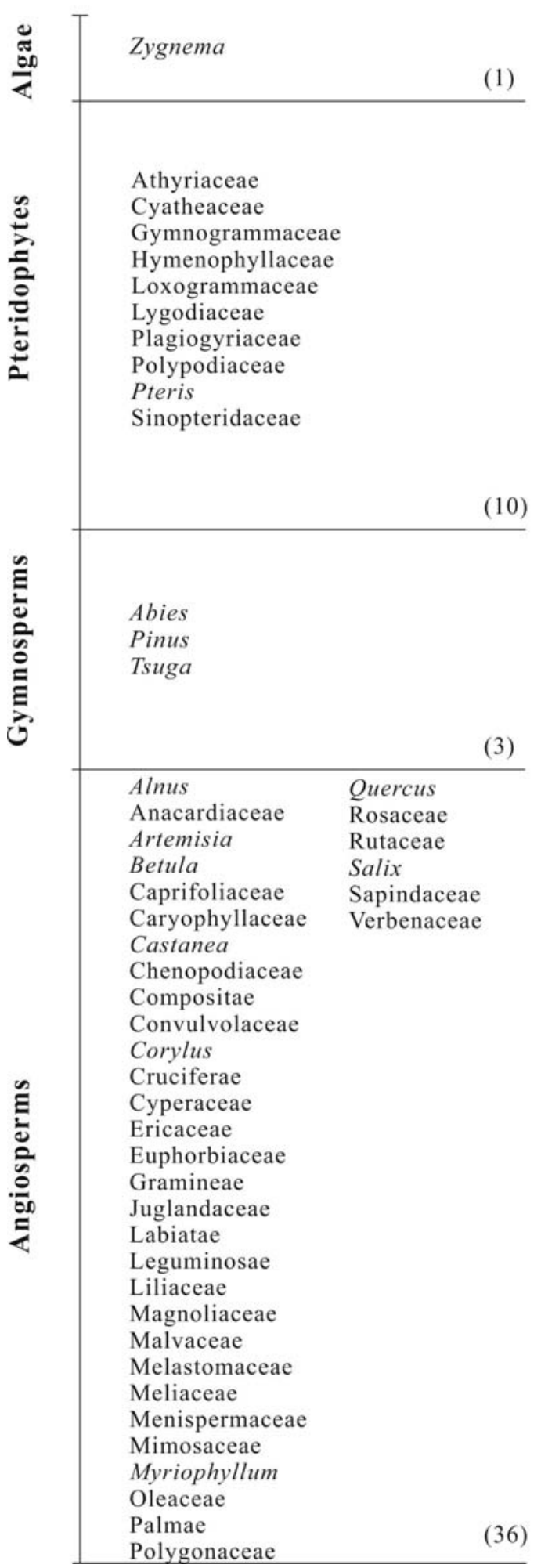

Core sediments

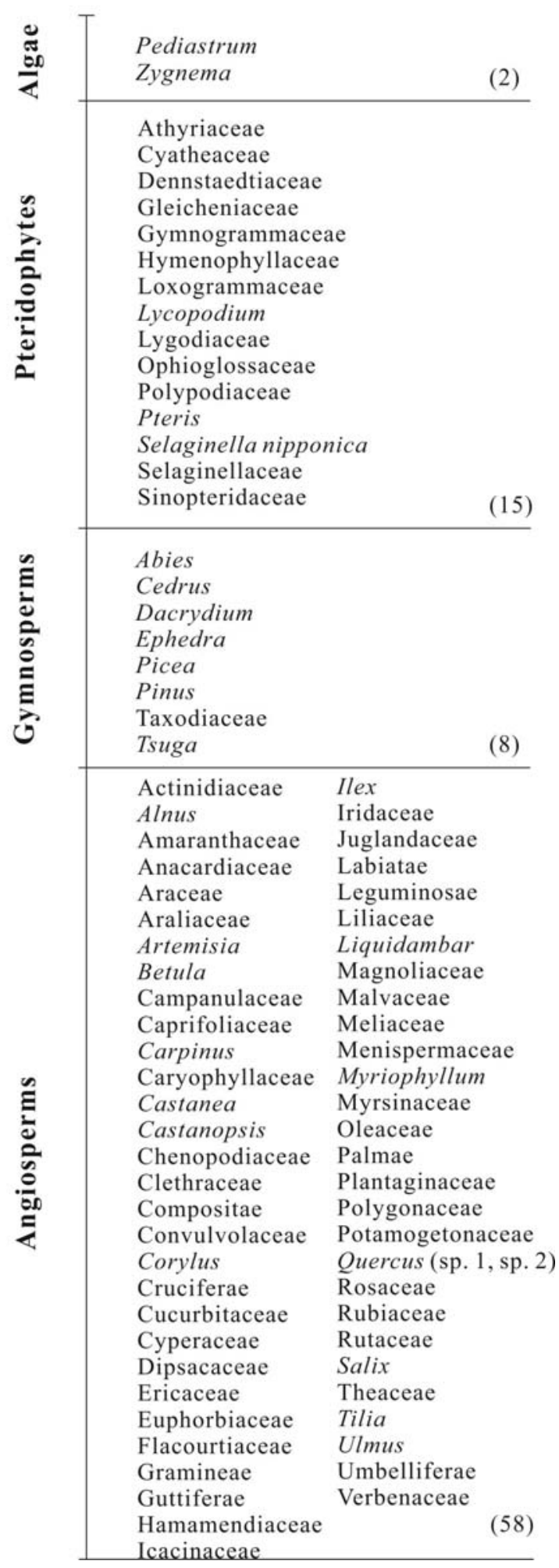

Figure S1 

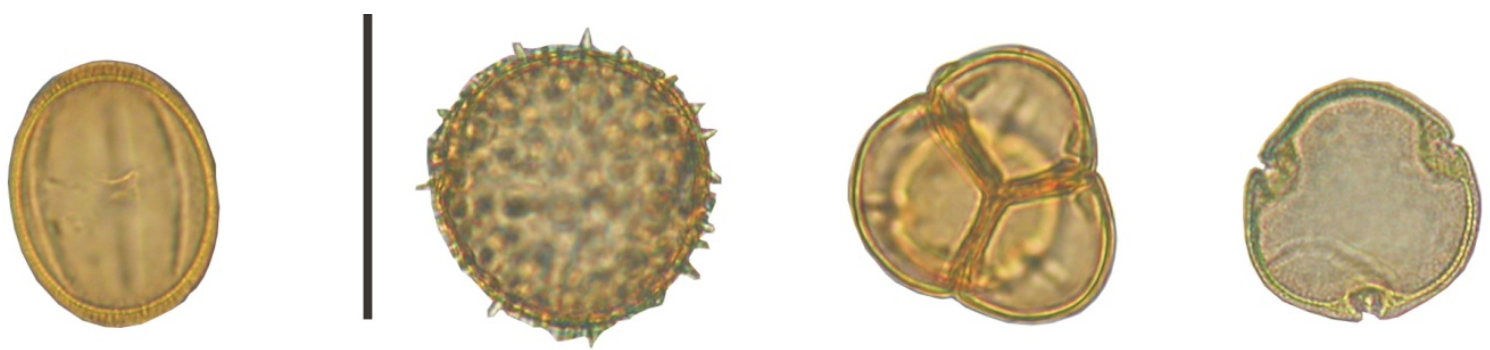

1

2

3

4
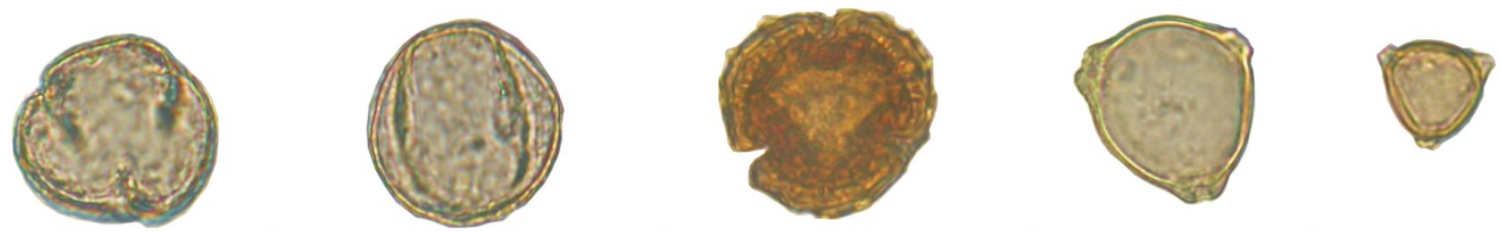

6

7

9
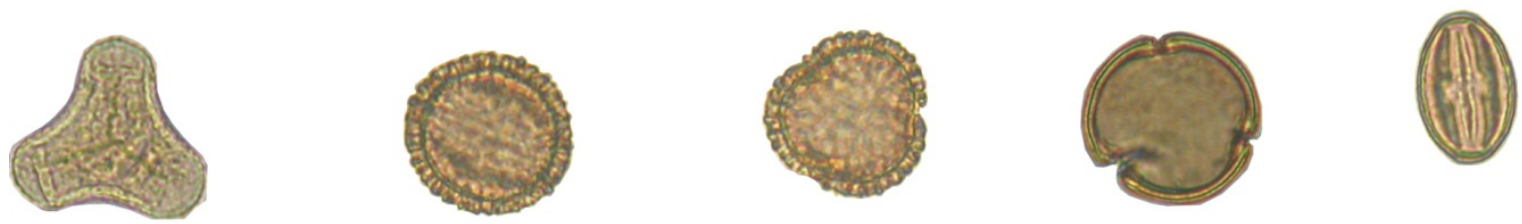

10

11

12
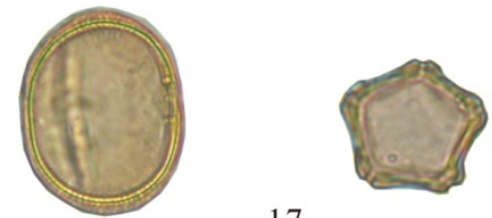

13

14
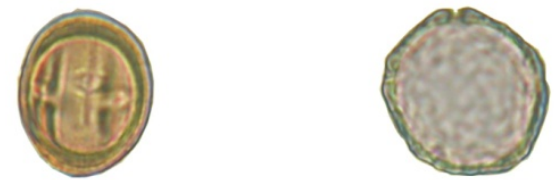

16

17
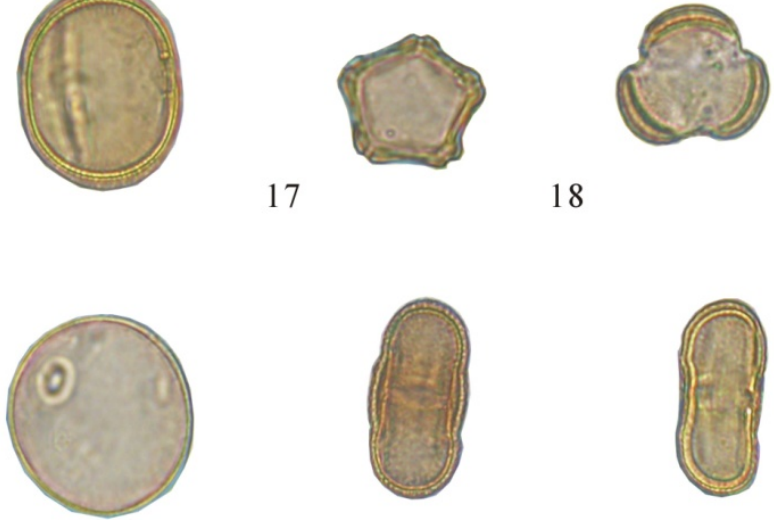

18

19
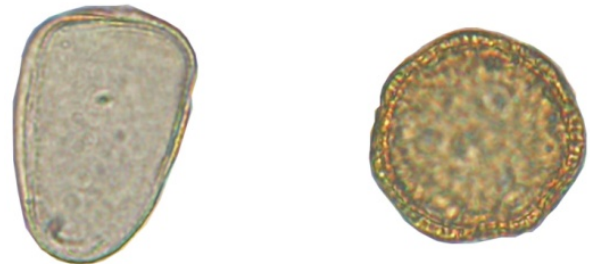

21

22

23

24

Figure S2 

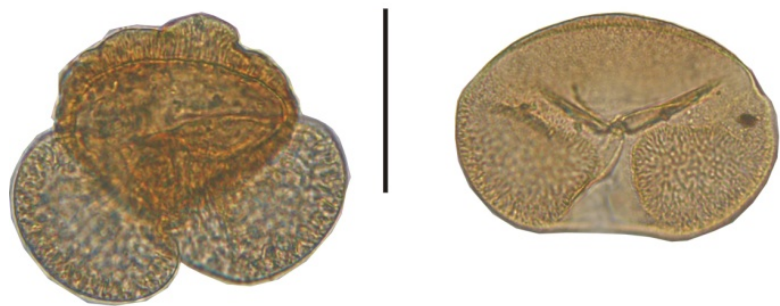

1
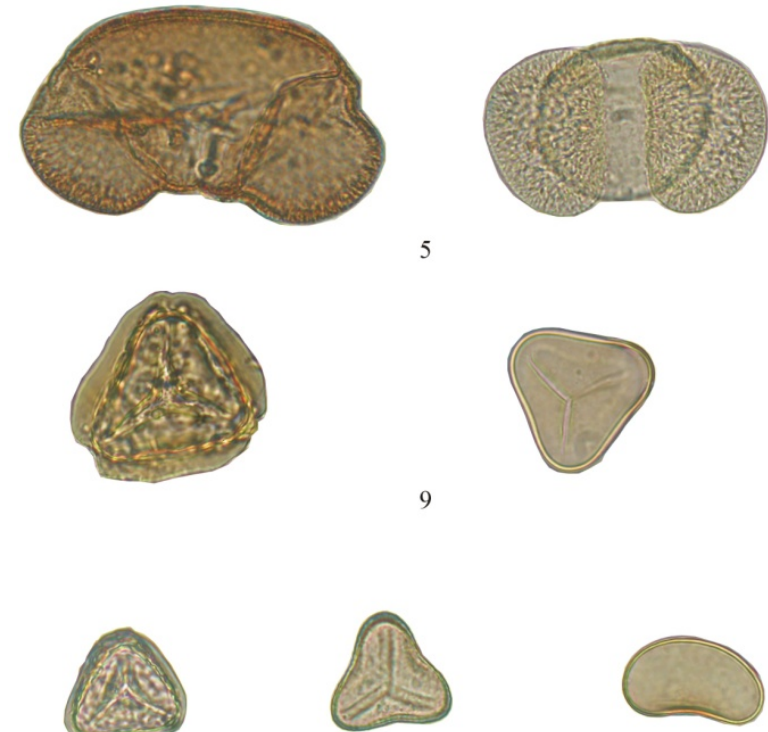

13

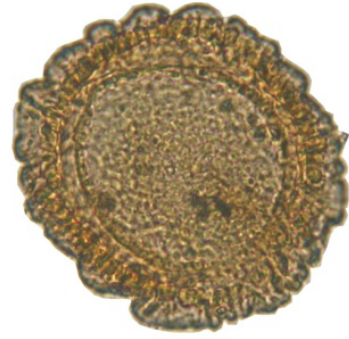

2

6

10

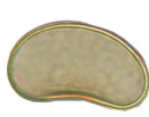

14
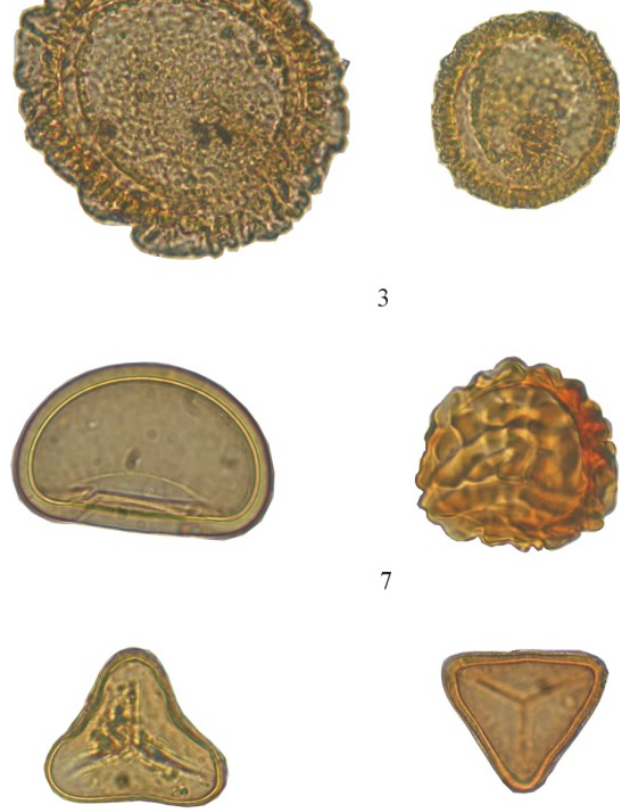

4

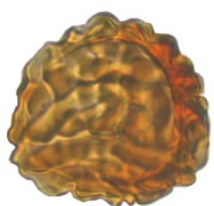

8

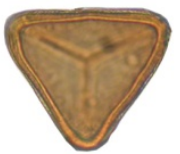

12
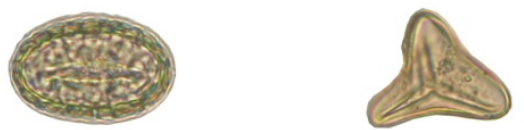

15

Figure S3 